\title{
O CAPITAL INTELECTUAL E A FORMAÇÃO DE VALOR EM EMPRESAS INTENSIVAS EM CAPITAL DE RISCO ${ }^{1}$
}

\author{
THE INTELLECTUAL CAPITAL AND THE FORMATION OF VALUE IN \\ INTENSIVE FIRMS IN VENTURE CAPITAL
}

\begin{abstract}
Adilson Celestino Lima² Charles Montreil Carmona ${ }^{3}$

RESUMO: Essa pesquisa teve como objetivo determinar os direcionadores de valor de empresas de tecnologia da informação e comunicação, notadamente em empresas com alto grau de capital de risco. Foi usada a estatística multivariada através da análise fatorial, para determinar os fatores geradores de valor que representassem um determinado direcionador de valor e também o modelo de equação estrutural para poder criar um modelo estrutural e formalizar as relações entre as variáveis e determinar os coeficientes da regressão, gerando variáveis não observadas até chegar a outra variável, essa de segundo grau, que foi determinada de Capital Intelectual ou Capital Intangível. Com base no modelo gerado, podemos afirmar que, numa empresa de predominância intangível, como no caso das empresas de tecnologia da informação e comunicação, o capital intangível é formado pelo Capital Humano; a Gestão do Capital Humano; o Capital Estrutural e, finalmente, o Ambiente Organizacional.
\end{abstract}

PALAVRAS-CHAVE: Avaliação de empresas. Capital intangível. Capital intelectual. Tecnologia da informação e comunicação.

ABSTRACT: this research aimed to determine the value of companies Directors of information and communication technology, especially in companies with a high degree of risk capital. Was used to multivariate statistics through factor analysis, to determine the factors generating value representing a particular Director value and also the structural equation model to create a structural model and formalize the relationships between the variables and determine the coefficients of regression, generating variables not observed until you reach the other variable, this second degree, which was determined in Intellectual Capital or Intangible Capital. On the basis of the generated model, we can say that, in an enterprise of intangible predominance, as in the case of companies of information technology and communication, the intangible capital is formed by Human Capital; Human Capital Management; Structural Capital and, finally, the organizational environment.

KEYWORDS: assessment of companies. Intangible Capital. Intellectual Capital. Information and communication technology.

\footnotetext{
${ }^{1}$ Artigo Recebido em 19.07.2010. Revisado por pares em 03.11.2010. Recomendado em 28.10.2010 por Leomar dos Santos Editor. Publicado em 28.10.2010.

Organização Responsável pelo periódico: Universidade regional de Blumenau - FURB - www.furb.br/rn
}

\footnotetext{
${ }^{2}$ Universidade Federal Rural de Pernambuco- UFRP -celestinolima@yahoo.com.br

${ }^{3}$ Universidade Federal de Pernambuco- UFP - charles_carmona@yahoo.com.br
} 


\section{INTRODUÇÃO}

Esse trabalho trata de empresas de Tecnologia da Informação e Comunicação - TIC (especificamente de empresas produtoras de software), setor no qual as variáveis básicas da macroeconomia não são tão óbvias. Deve-se, portanto, avaliar, de forma extremamente cuidadosa, o grau de resposta que tais variáveis proporcionam ao segmento.

Ao se tratar de empresas de tecnologia da informação e comunicação, doravante chamada de TIC, deve-se ter com clareza a sua diferença em relação às empresas de manufatura e comércio, uma vez que as empresas de TIC são quase que totalmente formadas por capital intelectual, logo sem oferecer patrimônio tangível como garantia, e suas fontes de financiamentos são basicamente capital de risco.

Como se tem observado nos últimos anos, tem-se intensificado o processo de busca de um modelo de avaliação do capital intelectual dessas empresas, verificando-se desta forma, que estas empresas são de difícil mensuração monetária, pois a quase totalidade do seu valor está concentrado no intangível.

Ao se chegar à conclusão de que o capital intangível é o mais importante dentro de uma empresa, como então fazer para avaliá-lo e determinar quais os elementos que produzem esse capital? Necessita-se, então, criar mecanismos para identificar os fatores geradores de valor e como se dá esse processo.

Como as empresas de tecnologia possuem uma lógica própria, cujo capital intangível é praticamente todo o capital desse tipo de empresa e seu nível de risco, tanto operacional quando financeiro é elevado, deve-se buscar, então, através de uma adequada caracterização, indicar como essas empresas criam valor.

Por ser a área de valuation uma área bastante eclética (possui uma grande interação com áreas como estratégias, economia, finanças, gestão de pessoas, marketing e também operações), faz-se necessário, para efeito de avaliação do capital intelectual, de uma maior aproximação da área de finanças, principalmente com a área a gestão de recursos humanos, uma vez que diversos estudos têm sido desenvolvidos no sentido de elucidar a estrutura do capital intelectual: isso passa, inevitavelmente, por entender a questão comportamental dentro das empresas no tocante ao quadro de pessoal. Trabalhos como o de Cardoso (2003), Bontis (1998, 2001), Moon e Kym (2007), Sveiby (1997), Edvisson e Malone (1998) entre outros, têm buscado trabalhar no sentido de mostrar a importância do capital intelectual na formação de valor numa empresa. Diante disso, o capital intelectual tem-se tornado tema relevante e também preocupante, uma vez que os instrumentos disponíveis, principalmente pela contabilidade, não conseguem, ainda, dar respostas em relação à formação do capital intangível das empresas e, sobretudo empresas de tecnologia da informação, que são intensivas em capital intangível e nelas prevalece o capital humano; porém, não só capital humano, mas também outros indicadores de criação de valor, que precisam de melhor evidenciação e mensuração.

\section{ATIVOS INTANGÍVEIS}

Existe, atualmente, um crescente interesse no estudo dos ativos intangíveis, particularmente do capital intelectual. No processo de avaliação, busca-se o valor total de uma 


\section{O CAPITAL INTELECTUAL E A FORMAÇÃO DE VALOR EM EMPRESAS INTENSIVAS EM CAPITAL DE RISCO}

empresa e, nesse processo, normalmente não se distingue o que é valor tangível e o que é valor intangível. Na realidade, atribui-se ao intangível (de forma grosseira) a diferença entre o valor total (valor avaliado pelo mercado) e o valor patrimonial, que é apurado via o Balanço.

Em termos de definição, existem algumas terminologias para os ativos intangíveis, que são bastante utilizadas, tais como: capital intelectual (STEWART, 1998) e (EDVINSSON; MALONE, 1998); ativos de conhecimento (SVEIBY, 1997); ativos invisíveis (SVEIBY, 1997); capital organizacional (CORNELL, 1993) e (BRYNJOLFSSON; HITT; YANG, 2002).

De acordo com Kayo (2002), tem crescido muito, nos últimos anos, a relação entre o valor de mercado e o valor contábil, tendo aumentado numa razão de 6 para 1 dos anos 80 até a atual década, ou seja, o valor de mercado tem sido, em média, seis vezes maior que o valor contábil. Essa diferença é plenamente atribuída ao capital intangível e, particularmente, ao capital intelectual, por isso, a importância de se estudar o capital intelectual.

Para Feltham e Ohlson (1995), o intangível é resultante dos lucros acima do normal, ou mesmo excesso de lucros. Lev (2001) também compartilha dessa visão, justificando também que um dos motivos que faz com que os intangíveis sejam de difícil avaliação é a não existência de mercados comparativos.

Bontis (1998) procura fazer a distinção entre intangíveis e capital intelectual. Para ele, capital intelectual não inclui ativos de propriedade intelectual, marcas registradas, patentes e vários outros direitos que são passíveis de registros na Contabilidade. Para esse mesmo autor, o capital intelectual não é apenas um intangível estático, mas sim um processo ideológico. $\mathrm{Na}$ visão de Lev (2001), o ativo intangível pode ser definido como um direito a benefícios futuros, que não possui corpo físico ou financeiro. Para Really e Schweihs (1998), o valor de um ativo intangível é criado por sua natureza intangível e não depende da sua natureza física. Para esses mesmos autores, a identificação de valor nos intangíveis equivale a uma pesquisa de caráter exploratório.

Shiu (2006, p. 356) chama a atenção para a necessidade da criação de novas abordagens econômicas para mensurar o desempenho corporativo, usando o capital intelectual como principal fator de produção. De acordo com Kayo et al (2006), os ativos intangíveis criam valor de forma sustentada. Para esses mesmos autores, a visão de criação de valor é atualmente compartilhada entre as áreas de finanças e estratégias: essa última denomina o ativo intangível como recurso baseado em valor. Para esses mesmos autores, "a posse de recursos valiosos, raros, inimitáveis e insubstituíveis pode levar à geração de lucros anormais, que, em última análise, é responsável pela formação do valor da empresa” (KAYO ET AL., 2006, p.77).

A importância de se estudarem os ativos intangíveis é plenamente justificada pelo fato de que as empresas de TIC são intangível-intensivas, ou seja, no seu valor, predomina a porção intangível, que é representada, principalmente, pelo capital intelectual.

Apesar do intangível não ser só capital intelectual, mas também marcas, processos, clientes etc., esse trabalho está focado, no que tange ao tópico do intangível, especificamente ao capital intelectual. Essa decisão é consubstanciada pelo fato de que empresas de TIC, normalmente não possuem um apelo comercial forte e nem trabalham com marcas fortes, como as voltadas para os bens de consumo em geral. 
Stewart (1998) confirma a importância do capital intelectual ao afirmar que os gastos das empresas norte-americanas com bens de capital nos anos 90 estavam na faixa de U\$110 bilhões. Por outro lado, os investimentos em tecnologia da informação passaram de U\$49 bilhões em 1982 para U\$112 bilhões em 1991. Esses números, conforme o autor, confirmam a importância dos intangíveis, particularmente o capital intelectual na nova economia.

É importante não confundir Ativo Intangível com Goodwill, como é comum em algumas situações, pois o primeiro refere-se à ativos aos quais, a princípio, não pode ser atribuído valor monetário, enquanto o segundo indica uma espécie de ágio no valor de uma empresa em relação ao seu valor patrimonial. Para Edvinsson e Malone (1998), os intangíveis são aqueles que não possuem existência física, mas, assim mesmo, representam valor para a empresa. Para Sveiby (1997), ativos intangíveis são compostos pelo conjunto de competências, estrutura interna e estrutura externa, tendo o conhecimento como fio condutor. Para esse mesmo autor, a visão da organização como preponderantemente composta de ativos intangíveis é a passagem do velho mundo para o novo mundo, ou seja, para a nova economia. Isso sugere uma volta a Kuhn (2005) e sua mudança de paradigma, em cuja obra ele diz que, quando um determinado paradigma não mais funciona (avaliação baseada nos tangíveis), levando a uma determinada crise, surgirá então uma revolução que culminará com um novo paradigma (avaliação baseada nos intangíveis).

Para Vigorona (2004), 85\% do valor das empresas chilenas estão alocados nos ativos intangíveis. Esse mesmo autor faz um questionamento: se existe toda uma estrutura para cuidar do ativo tangível, que representa apenas 15\%, como contadores, auditores, gerentes financeiros etc., quem cuida formalmente dos $85 \%$ ? Para esse mesmo autor, existe luz no fim do túnel. A criação de ferramentas como EVA ${ }^{\circledR}$ (Economic Value Added), MVA (Market Value Added) e TSR (Total Shareholder Return) é o primeiro passo real para a valorização dos intangíveis. Para Sveiby (1997), o Balanced Scorecard ${ }^{\circledR}$ (Kaplan e Norton, 1992) também é uma boa tentativa de aglutinar as medidas financeiras e as medidas de avaliação baseadas no conhecimento.

Sveiby (1997), quando trata de avaliação de intangíveis, afirma o seguinte: “Ao avaliarmos ativos intangíveis, devemos, portanto, estar preparados para dar prosseguimento às avaliações de modo a cobrir, pelo menos, três ciclos de avaliação antes de tentar avaliar os resultados. O ideal é que as avaliações sejam repetidas anualmente” (SVEIBY, 1997, p. 196).

Para Edvinsson e Malone (1998), Perez e Famá (2006) entre outros, a contabilidade não acompanhou a evolução do processo de avaliação e criação de valor. Para Lev (2001b), a contabilidade é relativamente forte para avaliar ativos tangíveis e relativamente fraca para avaliar ativos intangíveis. No entanto, como deveria a contabilidade mensurar ativos intangíveis como o capital intelectual? Essa é uma pergunta que ainda perdura e será necessário muito esforço, principalmente da academia, para encontrar meios e maneiras (modelos) que se apresentem como um consenso para definir e contabilizar tais ativos.

\subsection{Capital intelectual}

Para Vigorona (2004), capital intelectual é a riqueza invisível das organizações. Para Edvinsson e Malone (1998), o valor de uma empresa não reside nos tijolos e argamassas nem nos estoques, mas sim, no capital intelectual. Cardoso (2003) afirma que o capital intelectual é 


\section{O CAPITAL INTELECTUAL E A FORMAÇÃO DE VALOR EM EMPRESAS INTENSIVAS EM CAPITAL DE RISCO}

geralmente conceituado como a média aritmética de todos os tipos de capital envolvidos nos processos organizacionais. Para Edvinsson e Malone (1998, p. 10), o que torna o capital intelectual interessante é "o estudo das raízes do valor de uma empresa, a mensuração dos fatores dinâmicos ocultos que embasam a empresa visível formada por edifícios e produtos”. Para eles, esses fatores são: o capital humano, através do conhecimento, da experiência e a habilidade dos empregados e o fator inovação. O outro fator está relacionado ao capital estrutural, como softwares, bancos de dados, marcas e relacionamentos com os clientes, dentre outros. Dessa forma, a junção desses fatores constitui o capital intelectual.

Ainda citando Edvinsson e Malone (1998, p. 11), dizem eles que “o capital intelectual pode ser uma nova teoria, mas, na prática, está presente há anos como uma forma de bom senso. Sempre se esgueirou naquele valor resultante do quociente entre o valor de mercado de uma empresa e seu valor contábil”.

Ao contrário do senso comum de que o capital intelectual é fruto da subjetividade e também da forma como cada um enxerga e avalia a empresa, pode-se afirmar que, na realidade, esse capital é real e é fruto de elevados investimentos em capital humano, pesquisas e desenvolvimento e constitui, atualmente, o que se pode chamar de "o núcleo da economia do conhecimento", uma vez que, como citado anteriormente, o valor do intangível supera e muito o capital tangível na maioria das empresas.

Para Bontis (1998), o capital intelectual não inclui propriedade intelectual, como seria comum supor e propõe a figura 01 abaixo, dividindo o capital intelectual em capital humano, capital estrutural e capital do cliente ou relacional. Para esse mesmo autor, o conceito de capital intelectual é considerado de $2^{\mathrm{a}}$ ordem, enquanto o capital humano, o estrutural e o relacional são considerados de $1^{\mathrm{a}}$ ordem. A figura 01 abaixo apresenta algumas características fundamentais desses construtos.

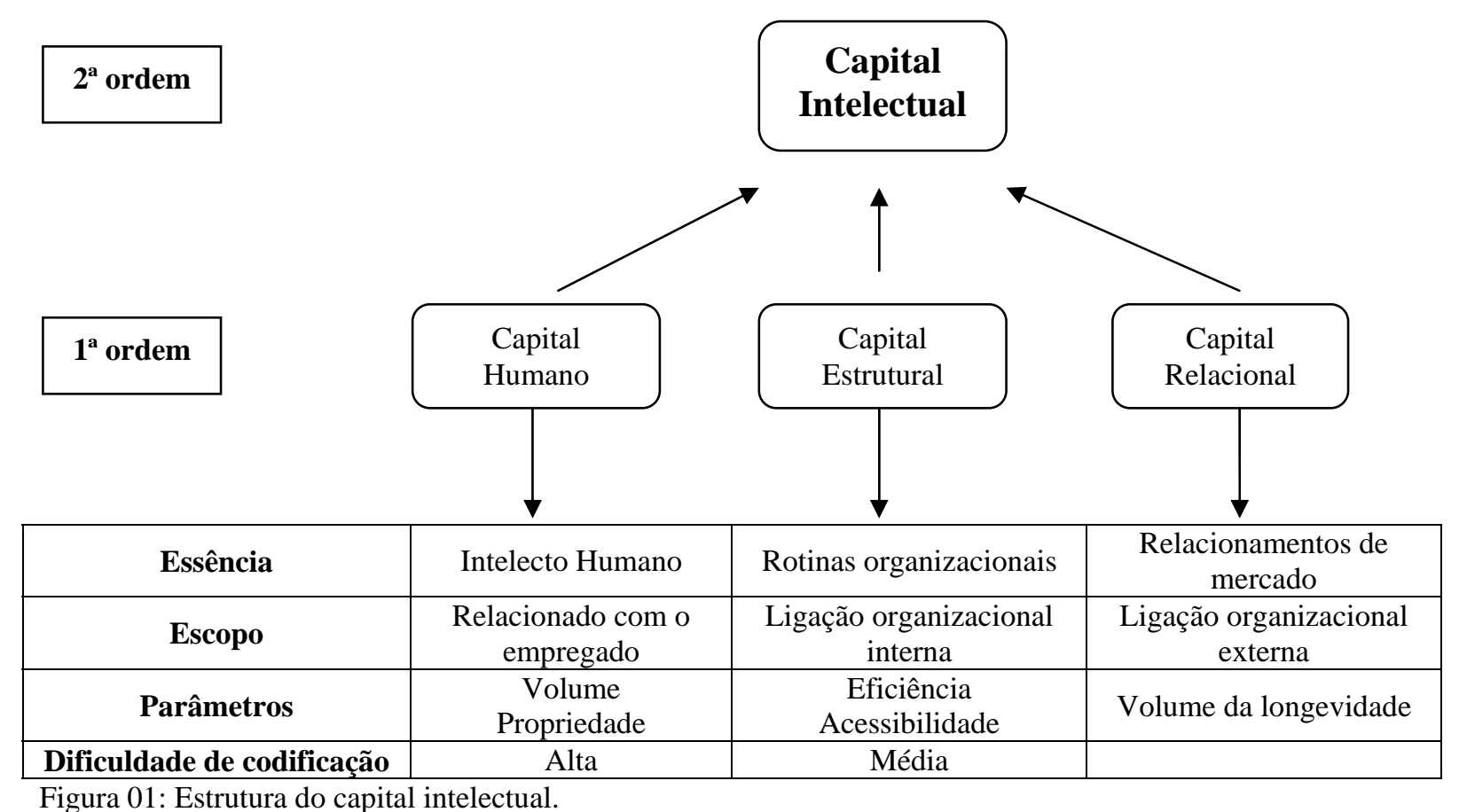

Figura 01: Estrutura do capital intelectual.

Fonte: Bontis (1998: 66). 
A tipologia acima apresentada e definida por Bontis (1998) é corroborada por diversos outros autores (CARDOSO 2003; SVEIBY 1997; EDVINSSON E MALONE 1998; LEV 2001 E KAPLAN E NORTON 1992).

Abrindo um pouco mais a estrutura apresentada por Bontis (1998), Cardoso (2003) tipifica o capital humano em: ativos humanos, processos de aprendizagem e recursos de competências no nível individual. Já o capital estrutural é composto, primordialmente, pelos processos internos, recursos de competência organizacional, infra-estrutura interna, clima organizacional e capacidade de gestão. Para a mesma autora, pode-se também atribuir ao capital estrutural a tudo aquilo que é gerado explicitamente pelos colaboradores, mas que esses não os levam para casa quando deixa a organização. São aqueles que contribuem para gerar e agregar valor e também resultados para a organização. Para o capital relacional, ou do cliente, na perspectiva de Kaplan e Norton (1992), está diretamente relacionado com a estrutura externa, nível de relacionamento com clientes e fornecedores e também a imagem no mercado.

\section{MÉTODO E MODELO DA PESQUISA}

Este trabalho teve como objetivo, identificar os fatores determinantes da formação do capital intangível/Intelectual nas empresas de TIC. Para isso, usou-se a pesquisa exploratória, na qual as variáveis a serem utilizadas no modelo final não estão ainda claramente definidas e carecendo de um construto lógico para relacioná-las a uma determinada teoria subjacente, buscando-se, dessa forma, identificar a relação das variáveis a serem exploradas com a formação do capital intangível das empresas de TIC e também a relação entre elas.

O instrumento utilizado para atingir tal propósito foi uma pesquisa de campo que teve o objetivo de identificar o pensamento dos empresários do citado segmento em relação à formação do capital intangível.

Para operacionalizar essa pesquisa, foi utilizada a Análise Multivariada, utilizando o seu aspecto exploratório, através da Análise Fatorial (Factor Analysis) e também o Modelo de Equação Estrutural (SEM).

\subsection{Levantamento dos dados}

A pesquisa foi realizada no Porto Digital, situado na cidade do Recife, estado de Pernambuco, que conta com um grande número de empresas, que vão desde empresas de serviço especializado como: banca de advogados e empresas de consultoria empresarial, passando por empresas de investimentos (fomentadores) e principalmente empresas de tecnologia da informação e comunicação (TIC). O Porto Digital é configurado como uma área de negócios e que não necessariamente congrega apenas empresas de tecnologia. É considerado um pólo de referência em termos de empresas de TIC em nível Brasil.

Os dados foram levantados a partir de um questionário aplicado às empresas de desenvolvimento localizadas no Porto Digital. Inicialmente, o questionário foi enviado via $e$ mail para todas as empresas de TIC do Porto Digital, ou seja, para toda a população. Como o nível de resposta foi muito baixo, equivalente a $5 \%$ do tamanho da população, optou-se por 


\section{O CAPITAL INTELECTUAL E A FORMAÇÃO DE VALOR EM EMPRESAS INTENSIVAS EM CAPITAL DE RISCO}

coletar as informações in loco, ou seja, realizar uma pesquisa de campo. Do total de 67 empresas de TIC, apenas 58 foram consideradas, uma vez que 9 (nove) empresas não estavam mais em atividade ou não foram localizadas. Do total das 58 empresas remanescentes, apenas 22 empresas se dispuseram a responder ao questionário, perfazendo um total de $38 \%$ de respondentes.

O questionário aplicado foi estruturado com respostas medidas na escala ordinal e de acordo com o grau de compreensão dos respondentes. A escala considerada foi de 1 a 5 , sendo o numeral 1 relacionado a mínima significância e 5 com a máxima significância em relação ao impacto de cada variável na formação do capital intangível. O quadro 01 a seguir, apresenta todas as variáveis utilizadas no questionário.

As respostas produzidas pelo questionário serviram de base para gerar a análise fatorial. Como se trabalhou com 36 variáveis, obtiveram-se 792 respostas que foram consideradas válidas para efeito de processamento da análise multivariada.

\subsection{Variáveis da pesquisa}

As variáveis utilizadas no questionário foram captadas de três fontes: as variáveis V1 (Conhecimento sobre o cliente), V3 (Capacitação dos colaboradores), V12 (Retenção dos melhores colaboradores), V16 (Processos da organização), V27 (Nível de satisfação dos colaboradores), V33 (Marcas e patentes) e V36 (Nível de relacionamento entre os sócios), foram definidas no trabalho de Moon e Kym (2006). As variáveis V2 (Respostas rápidas ao mercado), V5 (Nível de lucratividade), V9 (Participação de mercado), V11 (Desenvolvimento de novos produtos), V13 (Criação de valor para o cliente), V14 (Nível de comunicação interna) e V29 (Nível de criatividade dos colaboradores), foram extraídas e adaptadas do trabalho de Bontis (1998). As demais variáveis foram criadas pelo pesquisador.

O quadro 01 abaixo apresenta as variáveis da pesquisa no formato semelhante ao questionário, o qual consta no apêndice desta pesquisa.

\begin{tabular}{|c|c|c|c|c|c|}
\hline & $\begin{array}{c}\text { Variável } \\
\text { (Código) }\end{array}$ & Descrição & & $\begin{array}{c}\text { Variável } \\
\text { (código) }\end{array}$ & Descrição \\
\hline V1 & CONCI & Conhecimento sobre o cliente & V19 & ACTEC & $\begin{array}{c}\text { Acompanhamento da } \\
\text { tecnologia }\end{array}$ \\
\hline V2 & RESRM & Respostas rápidas ao mercado & V20 & MMNEG & $\begin{array}{c}\text { Manutenção do modelo de } \\
\text { negócio }\end{array}$ \\
\hline V3 & CAPCL & Capacitação dos colaboradores & V21 & CONGES & Continuidade da Gestão \\
\hline V4 & PROCL & Produtividade dos colaboradores & V22 & LIQEZ & Liquidez \\
\hline V5 & NLUCR & Nível de lucratividade & V23 & COINT & Controles internos \\
\hline V6 & BPGTA & Boas práticas de gestão & V24 & DEPTE & Dependência de terceiros \\
\hline V7 & ECTEN & Estrutura de custos enxuta & V25 & CLNSP & $\begin{array}{c}\text { Colaboradores com nível } \\
\text { superior ou pós-graduação }\end{array}$ \\
\hline V8 & NFTRA & Novas formas de trabalho & V26 & DTTRA & $\begin{array}{c}\text { Domínio das técnicas de } \\
\text { trabalho }\end{array}$ \\
\hline V9 & PARTM & Participação de mercado & V27 & NSTCL & $\begin{array}{c}\text { Nível de satisfação dos } \\
\text { colaboradores }\end{array}$ \\
\hline V10 & CCONE & $\begin{array}{r}\text { Criação de novas oportunidades de } \\
\text { negócios }\end{array}$ & V28 & QAMBT & $\begin{array}{c}\text { Qualidade do ambiente de } \\
\text { trabalho }\end{array}$ \\
\hline V11 & DESPR & $\begin{array}{r}\text { Desenvolvimento de novos } \\
\text { produtos }\end{array}$ & V29 & NCRCL & $\begin{array}{c}\text { Nível de criatividade dos } \\
\text { colaboradores }\end{array}$ \\
\hline
\end{tabular}




\begin{tabular}{|c|c|c|c|c|c|}
\hline V12 & REMCL & $\begin{array}{c}\text { Retenção dos melhores } \\
\text { colaboradores }\end{array}$ & V30 & EPRIN & $\begin{array}{c}\text { Eficiência dos processos } \\
\text { internos }\end{array}$ \\
\hline V13 & CVLCI & Criação de valor para o cliente & V31 & QPOSV & Qualidade do pós-venda \\
\hline V14 & NCOMI & Nível de comunicação interna & V32 & POLIN & Política de incentivos \\
\hline V15 & GINOV & Grau de inovação & V33 & MAPAT & Marcas e patentes \\
\hline V16 & PROOR & Processos da organização & V34 & RELFO & $\begin{array}{c}\text { Relacionamento com } \\
\text { fornecedores }\end{array}$ \\
\hline V17 & CAPAP & Capacidade de aprendizado & V35 & LEACI & Lealdade dos clientes \\
\hline V18 & RETIN & Retorno dos investimentos & V36 & NRSOC & $\begin{array}{c}\text { Nível de relacionamento } \\
\text { entre os sócios }\end{array}$ \\
\hline
\end{tabular}

Quadro 01: Variáveis da pesquisa.

\subsection{Confiabilidade das variáveis}

Primeiramente, para se ter segurança em termos da confiabilidade dos construtos, deve-se verificar o grau de confiabilidade das variáveis em termos de fator de carga, ou suas variâncias. A estatística mais comum é o Alfa de Cronbach (Hair et al., 2005; Bontis, 1998 e Moon e Kym 2006). Esse indicador revela se as variáveis utilizadas para definir um determinado construto são confiáveis ou não. Para isso, caso seu resultado seja inferior a 0,7 (deve-se situar em 0 e 1) indica que a variável não é representativa e não homogênea em relação às demais variáveis e deverá ser excluída da amostra.

O quadro 02 abaixo apresenta o resultado global de todas as variáveis utilizadas na pesquisa, obtendo-se o escore médio de 0,917, isso é, bem acima do mínimo necessário. O Alfa de Cronbach foi calculado utilizando o SPSS versão 16.0.

\begin{tabular}{|c|c|c|}
\hline Alfa de Cronbach & $\begin{array}{c}\text { Alfa de Cronbach baseada em itens } \\
\text { padronizados }\end{array}$ & $\mathrm{N}^{\circ}$ de itens \\
\hline 0,917 & 0,920 & 36 \\
\hline
\end{tabular}

Quadro 02: Confiabilidade estatística

\subsection{Definição dos fatores}

O fato de a análise fatorial definir os fatores, associados às dimensões latentes (cargas ou autovalores ou eigenvalue), não exime o pesquisador da fundamentação teórica das relações a serem geradas pela análise, ou seja, as relações devem ser suportadas por uma teoria ou fortemente justificada quando se tratar de uma nova teoria.

A análise fatorial tem, também, como objetivo fundamental, a redução do número de variáveis, agrupando, ao máximo possível, determinadas variáveis, formando construtos lógicos que representem uma teoria consistente. Diversos autores, entre eles Hair et al. (2005), Arbuckle (2005), Aranha e Zambaldi (2008), recomendam que, na formação dos fatores, o ideal seria um número entre 3 e 5 (fatores), e que eles possam representar a teoria pretendida e que suas cargas sejam representativas em termos de variância total.

Para a formação dos fatores, foi definido inicialmente, por hipótese, que cada variável deveria possuir fator de carga igual ou superior a 0,70 (capacidade de explicação da variância total da própria variável) e que cada fator deveria possuir autovalores (eigenvalue) igual ou maior que 1, conforme recomendado por Hair et al. (2005) e também já presente no default da maioria dos programas como o SPSS e Statistica. 


\section{O CAPITAL INTELECTUAL E A FORMAÇÃO DE VALOR EM EMPRESAS INTENSIVAS EM CAPITAL DE RISCO}

Após sucessivas rodadas, chegou-se ao que foi considerado adequado, formando 4 fatores, com 10 variáveis e com mais de 86,97\% (conforme a tabela 4.3 a ser exibida na seção referente a resultados da pesquisa) de explicação da variância total e com um nível razoável de adequação da amostra. Como esse resultado foi considerado satisfatório, uma vez que preenche os requisitos de formação de fatores consistentes e também se localiza dentro do intervalo considerado adequado e excelente nível de explicação da variância total, decidiu-se por não mais ajustar a amostra. As variáveis e suas respectivas cargas são apresentadas na tabela 01 na seção referente a resultados da pesquisa.

Tabela 01: Método de extração: análises de componentes principais

\begin{tabular}{c|l|l|c|c|c|c}
\hline Var. & Código & Descrição & Fator $\mathbf{1}$ & Fator $\mathbf{2}$ & Fator 3 & Fator $\mathbf{4}$ \\
\hline V3 & CAPCL & Capacitação dos colaboradores & $\mathbf{0 , 9 0 1}$ & 0,222 & 0,167 & 0,094 \\
\hline V4 & PROCL & Produtividade dos colaboradores & $\mathbf{0 , 9 0 6}$ & 0,165 & 0,119 & 0,263 \\
\hline V5 & NLUCR & Nível de lucratividade & 0,213 & 0,195 & $-0,145$ & $\mathbf{0 , 9 0 2}$ \\
\hline V12 & REMCL & Retenção dos melhores colaboradores & $-0,113$ & $\mathbf{0 , 9 1 0}$ & 0,031 & 0,009 \\
\hline V14 & NCOMI & Nível de comunicação interna & 0,028 & 0,223 & $\mathbf{0 , 9 0 2}$ & $-0,132$ \\
\hline V15 & GINOV & Grau de inovação & $\mathbf{0 , 8 4 4}$ & $-0,020$ & $-0,342$ & 0,223 \\
\hline V17 & CAPAP & Capacidade de aprendizado & 0,278 & $\mathbf{0 , 7 7 8}$ & 0,157 & 0,241 \\
\hline V21 & CONGES & Continuidade da gestão & 0,008 & 0,050 & $\mathbf{0 , 9 5 1}$ & $-0,053$ \\
\hline V28 & QAMBT & Qualidade do ambiente de trabalho & 0,391 & $\mathbf{0 , 7 2 9}$ & 0,193 & 0,090 \\
\hline V33 & MAPAT & Marcas e patentes & 0,204 & 0,051 & $-0,063$ & $\mathbf{0 , 9 4 5}$ \\
\hline
\end{tabular}

Método de Rotação: Varimax.

Os fatores selecionados apresentam significância estatística, tendo apresentado KMO, como teste de adequação da amostra, equivalente a 0,613 e esfericidade, através do quiquadrado e seus graus de liberdade, apresentando significância de 0,000. Estes dados são apresentados no quadro 03 abaixo.

\begin{tabular}{|l|c|}
\hline Medida de adequação da amostra (KMO) & 0,613 \\
\hline Teste de Esfericidade & \\
\hline Qui-quadrado & 134,992 \\
\hline Graus de liberdade & 45,000 \\
\hline Significância & 0,000 \\
\hline
\end{tabular}

Quadro 03: teste de adequação da amostra.

Como pode ser observado no quadro acima e usando o método exploratório, os quatros fatores que emergiram da análise fatorial apresentam itens com capacidade de explicar 86,97\% do total da variância possível. Esse resultado é bastante robusto, cabendo agora definir esses construtos e formar um referencial teórico que fundamente a formação desses fatores. Os construtos definidos são os seguintes, conforme o quadro 04 abaixo:

\begin{tabular}{|c|c|c|}
\hline Fator & Construto & Variáveis \\
\hline 1 & Capital Humano & $\begin{array}{ll}\text { - } & \text { Capacitação dos colaboradores (CAPCL) } \\
\text { - } & \text { Produtividade dos colaboradores (PROCL) } \\
\text { - } & \text { Grau de inovação (GINOV) } \\
\end{array}$ \\
\hline 2 & Gestão do Capital Humano & $\begin{array}{ll}\text { - } & \text { Retenção dos melhores colaboradores (REMCL) } \\
\text { - } & \text { Capacidade de aprendizado (CAPAP) } \\
\text { - } & \text { Qualidade do ambiente de trabalho (QAMBT) } \\
\end{array}$ \\
\hline
\end{tabular}




\begin{tabular}{|c|c|ll|}
\hline 3 & Ambiente Organizacional & $\begin{array}{l}\text { Nível de comunicação interna (NCOMI) } \\
\bullet\end{array}$ \\
\hline 4 & Capital Estrutural & $\begin{array}{l}\text { ・ Nível de lucratividade (NLUCR) } \\
\bullet\end{array}$ \\
\hline
\end{tabular}

Quadro 04: Fatores e construtos.

O primeiro construto, que recebeu o atributo de Capital Humano, é considerado o principal fator dentro da estrutura do Capital Intelectual e também de fundamental importância entre os intangíveis. Esse construto é composto pelas variáveis CAPCL, PROCL e GINOV. Essas variáveis, com base nos resultados alcançados, representam 26,76\% de toda a variância explicada (com a carga rotacionada). Por conta da sua natureza, essas variáveis estão diretamente relacionadas com a qualidade da mão-de-obra disponível na empresa e sua importância para a formação do valor. Apesar de outras variáveis guardarem também relação com o capital humano, apenas essas três se apresentaram como as mais representativas no ponto de vista dos respondentes. Esse resultado encontra respaldo nos trabalhos de Bontis (1998, 2001), Moon e Kym (2006), Cardoso (2003) e Chang (2005). Apesar desses trabalhos não envolverem as mesmas variáveis, variáveis por eles utilizadas indicam que todas as variáveis relacionadas diretamente à capacidade produtiva dos colaboradores implicam capital humano.

O segundo fator encontrado, denominado de Gestão do Capital Humano, obteve eigenvalue igual a 21,35\% e é representado pelas seguintes variáveis: Retenção dos Melhores Colaboradores (REMCL), Capacidade de Aprendizado (CAPAP) e Qualidade do Ambiente de Trabalho (QAMBT). Acredita-se tratar de variáveis que possuem grandes semelhanças em termos de significado e que devem estar amparadas numa política de recursos humanos, que poderá proporcionar ambiente propício para gerar novas idéias e, conseqüentemente, agregação de valor. Como se verifica na tabela 01, que trata das cargas representativas de cada construto, percebe-se que apenas a variável REMCL possui carga superior a 0,9 e bem superior às outras variáveis que compõem o fator, indicando a sua superioridade em relação às outras duas. Diante disso, percebe-se claramente o quanto é importante e valioso para uma organização, principalmente na visão dos gestores de empresas de TIC, a gestão dos recursos humanos e o tratamento diferenciado que os colaboradores dessas empresas recebem em relação a horários e flexibilidade em relação ao trabalho.

O terceiro fator, chamado de Ambiente Organizacional, com eigenvalue de 19,66\%, está representado pelas variáveis Nível de Comunicação Interna (NCOMI) e Continuidade da Gestão (CONGES). Essas variáveis são consideradas como essenciais para um bom Ambiente Organizacional, indicando que, caso uma empresa possua clareza no seu processo de comunicação (direção / colaboradores) e também um entendimento que os gestores darão continuidade aos seus processos e, também, sabendo e conhecendo como a empresa é e possivelmente será gerida, contribui fortemente para a formação de valor. É de conhecimento comum que empresas que efetuam mudanças constantes de comando só o fazem por problemas no processo gerencial, logo, a continuidade, quando dá certo, representa valor. Como se observa na tabela 01, essas variáveis possuem poder de carga elevado e com alto grau de explicação do que ocorre de fato com esse fator, restando pouco para ser explicado 


\section{O CAPITAL INTELECTUAL E A FORMAÇÃO DE VALOR EM EMPRESAS INTENSIVAS EM CAPITAL DE RISCO}

pelas variáveis não observadas (NCOMI $=0,902$ e CONGES $=0,951)$. Isso indica uma elevada convicção dos respondentes em relação a essas variáveis como criadoras de valor.

O último fator, Capital Estrutural, com eigenvalue de 19,20\%, formado também por apenas duas variáveis, não deixa dúvida quanto a sua capacidade explicativa. A variável Nível de Lucratividade (NLUCR) apresenta fator de carga de 0,902, e a variável Marcas e Patentes (MAPAT) apresenta fator de 0,945. Como se vê, são variáveis importantes e, através da combinação de ambas, seria adequado chamá-las de Capital Estrutural. Esse atributo é bastante utilizado em trabalhos que envolvem a identificação do capital intelectual e é considerado como um atributo padrão, mesmo apresentando variáveis diferentes (Bontis 1998, 2001; Moon e Kym 2006, Cardoso 2003 entre outros). Conforme Moon e Kym (2006), o capital estrutural é o menos óbvio e requer uma maior especificação. Pode-se incorporar como capital estrutural variáveis como sistema de informação e processos, assim como elementos que possam proporcionar segurança à empresa em relação ao mercado e aos concorrentes.

\section{O MODELO ESTRUTURAL}

Para rodar o modelo de equação estrutural, foi utilizado o software AMOS $^{\mathrm{TM}}$ na versão 6.0, usando a interface com o SPSS. O objetivo é mostrar como as variáveis observadas (variáveis independentes) se relacionam com as variáveis não observadas (fatores), que nesse caso, são as variáveis dependentes, gerando uma relação de primeira ordem. Como tais variáveis não observáveis se relacionam com outra variável, também não observável, passa esta a ser, agora, a variável dependente, e forma uma relação de segunda ordem. Essa relação foi medida usando o coeficiente de correlação e, em seguida, transformada em fator de carga, que, por sua vez, representam os betas das equações de regressão. A tabela 02 abaixo apresenta as variáveis, seus construtos e seus coeficientes (betas). A primeira coluna apresenta as variáveis, sendo as quatro primeiras representadas pelos fatores construídos na análise fatorial, gerando o construto INTANGÍVEL e as demais apresentam as variáveis originais (observadas) que, por sua vez, geraram os fatores (variável dependente). A última coluna apresenta os coeficientes das regressões.

Tabela 02: Coeficientes padronizados da regressão.

\begin{tabular}{l|l|c}
\hline \multicolumn{1}{c|}{ Variável } & \multicolumn{1}{c}{ Construto } & Coeficiente \\
\hline Capital Humano (CH) & Intangível (INT) & 0,783 \\
\hline Gestão dos Recursos Humanos (GRH) & Intangível (INT) & 0,655 \\
\hline Ambiente Organizacional (AO) & Intangível (INT) & 0,564 \\
\hline Capital Estrutural (CE) & Intangível (INT) & 0,184 \\
\hline V3 - Capacitação dos Colaboradores & Capital Humano (CH) & 0,860 \\
\hline V4 - Produtividade dos Colaboradores & Capital Humano (CH) & 1,016 \\
\hline V15 - Grau de Inovação & Capital Humano (CH) & 0,745 \\
\hline V12 - Retenção dos Melhores Colaboradores & Gestão dos Recursos Humanos (GRH) & 0,629 \\
\hline V17 - Capacidade de Aprendizado & Gestão dos Recursos Humanos (GRH) & 0,745 \\
\hline
\end{tabular}




\begin{tabular}{l|l|c}
\hline V28 - Qualidade do Ambiente de Trabalho & Gestão dos Recursos Humanos (GRH) & 1,016 \\
\hline V14 - Nível de Comunicação Interna & Ambiente Organizacional (AO) & 0,996 \\
\hline V21 - Continuidade da Gestão & Ambiente Organizacional (AO) & 0,853 \\
\hline V5 - Nível de Lucratividade & Capital Estrutural (CE) & 0,623 \\
\hline V33 - Marcas e Patentes & Capital Estrutural (CE) & 1,273 \\
\hline
\end{tabular}

De acordo com entendimento de Moon e Kym (2006), um modelo estrutural, na sua plenitude, deverá ser avaliado enfocando os seguintes aspectos: a) consistência interna; b) validade convergente; e c) validade discriminante. Por consistência interna entende-se a qualidade dos dados e isso foi validado com o Alfa de Cronbach, apresentado anteriormente.

O Modelo Estrutural, apresentado através da saída do AMOS, conforme a figura 02, apresenta as relações entre as variáveis e seus construtos. As variáveis apresentadas nos retângulos representam as variáveis observadas e os círculos representam o erro ou o nível de variância não observada. As elipses representam os construtos ou as variáveis não observadas, e que são objeto da construção da teoria ou o que fundamenta as relações.

O modelo apresentado é caracterizado como um modelo recursivo por apresentar as seguintes características: a) as propostas de relação de causalidade estão em uma única direção; e b) cada variável tem efeito direto numa outra variável. As relações de causalidade se apresentam quando uma determinada variável influencia outra e essa, por sua vez, influencia uma terceira.

Como se observa, no primeiro construto, tem-se o Capital Humano relacionando-se com as variáveis V3, V4 e V15. As setas que ligam o Capital Humano às variáveis observadas estão acompanhadas dos seus respectivos coeficientes gerados pelo software. Nota-se que existe uma relação positiva entre essas variáveis e o Capital Humano, indicando que, quanto maior ou quanto mais importante forem essas variáveis para uma empresa, maior será o peso desse construto no valor total do Intangível. No entanto, esse não é um privilégio apenas desse construto, mais, sim, todos os quatro fatores. Essas relações se apresentam como relações de primeira ordem.

Como se apresenta na figura 02, a variável V4 (Produtividade dos Colaboradores) representa o maior nível de relação com o valor do Capital Humano, indicando que, para os gestores das empresas de tecnologia da informação e comunicação, a produtividade é mais importante que a capacitação e que o grau de inovação dos colaboradores. Isso é corroborado pela exclusão da variável V25 (Colaboradores com nível superior e ou pós-graduação) já na análise fatorial. Foi demonstrado que essa variável não é fundamental para a criação de valor, uma vez que foi excluída da amostra por não apresentar aderência ou correlação significativa, implicando que nesse segmento, que trabalha basicamente com quadro de pessoal muito enxuto, o importante é ser produtivo, logicamente com o mais alto grau de escolaridade possível.

Essas empresas trabalham muito com certificações (fornecidas pelas empresas de tecnologia) para seus colaboradores, ou seja, cursos de formação que são fornecidos pelo mercado e não necessariamente pelos cursos universitários.

Em relação ao construto Gestão dos Recursos Humanos, as variáveis representam pesos relativamente equilibrados, não apresentando nenhuma com participação muito relevante em relação às outras. Já no construto Ambiente Organizacional, percebe-se o quanto 
a variável V14 (Comunicação Interna) é preponderante. Ela representa mais que o dobro do peso da outra variável (V21 - Continuidade da Gestão). Pode-se afirmar que esse é um fenômeno amplo, denotando que, em qualquer tipo de empresa, mesmo com alto grau de especialização, a comunicação entre os colaboradores e principalmente dos gestores para os colaboradores, essa relação é primordial, mesmo se tratando da visão dos respondentes, que, nesse caso, são os próprios gestores.

Em relação ao último construto, encontra-se algo que era de se esperar para esse tipo de empresa. A variável V33 (Marcas e Patentes) possui menos importância que o Nível de Lucratividade desejada (V5). Como essas empresas não possuem apelo comercial, na sua grande maioria, essa variável se apresenta como menos relevante, mas, mesmo assim, importante.

Analisando a relação de segunda ordem (relação do Intangível com os quatro construtos), os resultados apresentados através dos coeficientes da regressão mostram a preponderância do Capital Humano como criador de valor, com coeficiente de 0,78. Em seguida, apresenta-se o construto Gestão dos Recursos Humanos, com coeficiente de 0,66. É latente que os colaboradores são os principais instrumentos de geração de valor para essas empresas, no entanto, existe preocupação com a estrutura da empresa (revelada pela pesquisa), representada tanto pelo Nível de Lucratividade que ela pode e deve apresentar e com uma Marca e ou mesmo produtos (softwares) que possam projetar a empresa para níveis mais altos de rentabilidade. Isso é, os recursos humanos são a essência, desde que proporcionem rentabilidade e lucratividade. Esse construto (Capital Estrutural) apresenta coeficiente de 0,56, 0,10 abaixo da Gestão dos Recursos Humanos, ou seja, um elevado grau de importância no conjunto do capital intangível. Já o Ambiente Organizacional, com coeficiente de 0,15 , não se apresenta como relevante para a criação de valor, quando comparado com os outros três fatores. Isso indica a não prioridade, na visão dos gestores, dessas variáveis (Comunicação Interna - V14 e Continuidade da Gestão - V21) no processo de criação de valor. Essa situação é confirmada pelo fato de que, em tais empresas, o grau de profissionalização ainda é relativamente baixo, com profissionais com formação preponderante em áreas técnicas (Informática e Engenharias) e possivelmente pouca vivência em gestão.

A figura 02 abaixo apresenta todas as relações padronizadas advindas do modelo de equação estrutural, usando os coeficientes de formação das equações e respaldando o que foi relatado acima. 


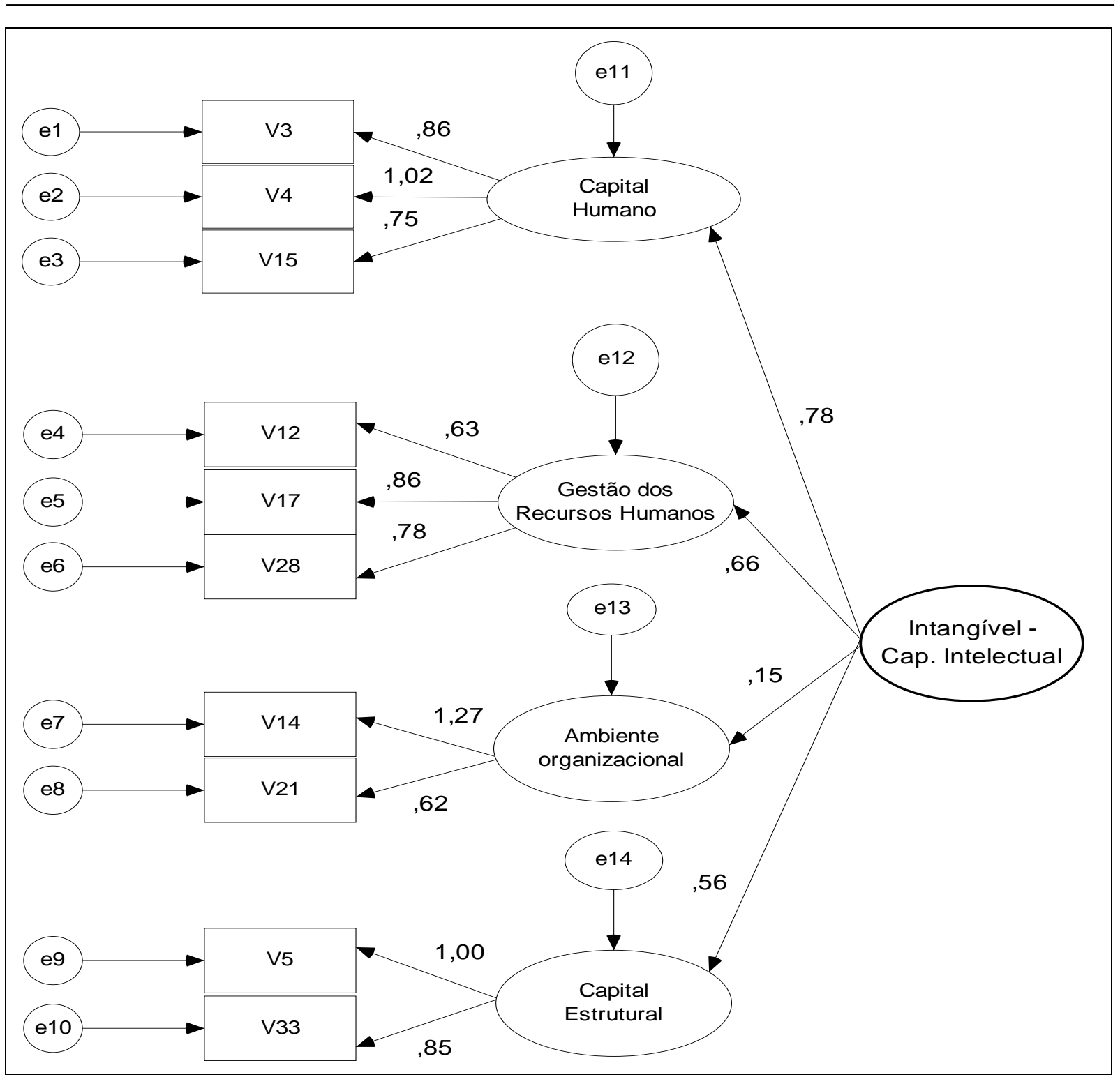

Figura 02: Modelo estrutural

Com base no que foi apresentado na figura 02 acima, pode-se, então, formar as equações geradas pelo Modelo de Equação Estrutural (SEM).

Da relação de primeira ordem:

$$
\text { C.HUMANO }(\mathrm{CH})=0,860 \mathrm{~V} 3+1,016 \mathrm{~V} 4+0,745 \mathrm{~V} 15+e
$$

GESTÃO RECURSOS HUMANOS $(G R H)=0,629 V 12+0,863 V 17+0,775 V 28+e$

AMBIENTE ORGANIZACIONAL $(A O)=1,273 V 14+0,623 V 21+e$

CAPITAL ESTRUTURAL $(C E)=0,996 V 5+0,853 V 33+e$

Da relação de segunda ordem:

$$
\text { INTANGÍVEL }=0,783 C H+0,655 G R H+0,148 A O+0,564 C E+e
$$




\subsection{A estatística do modelo estrutural}

Apesar de ainda ser uma técnica nova e com pouca aplicabilidade em áreas como Finanças, as estatísticas do modelo de equação estrutural estão ainda em fase de consolidação, sendo esta técnica, mais difundida nas áreas de Psicologia e também em Marketing.

Em princípio, não existe um teste definitivo nem o melhor teste, nem tampouco o melhor modelo, mas sim aquele que melhor se ajuste aos dados utilizados. As medidas, quando usadas em conjunto, proporcionam uma visão da qualidade do modelo (HAIR ET AL., 2005; ARBUCKLE, 2005; KLINE, 2005).

Os resultados são avaliados observando três perspectivas, quais sejam: o Ajuste Geral ou Absoluto (Model Fit Summary); Ajuste Comparativo com um Modelo Base ou Medidas de Ajuste Incremental (Baseline Comparisons) e a Parcimônia do Modelo ou Medida de Ajuste Parcimonioso (Parsimony-Adjusted Measures).

Conforme Arbuckle (2005), a avaliação de um modelo é uma das questões mais difíceis e instáveis relacionadas ao modelo estrutural, uma vez que existem vários pontos de vista e recomendações típicas. O que se busca é o modelo que melhor se ajuste aos dados e tenha o máximo de consistência teórica.

Dos poucos trabalhos que utilizaram o Modelo de Equação Estrutural para definir a formação do Capital Intelectual, uns utilizaram o GFI, AGFI, NFI e AIC, como estatísticas, a exemplo de Hsu (2007). Já Moon e Kym (2006) utilizaram basicamente o TLI e o AIC como estatísticas para definir a qualidade do modelo. No entanto, esse trabalho seguirá a recomendação de Arbuckle (2005), por apresentar uma análise mais abrangente, e serão utilizados tanto os indicadores apresentados por Hsu (2007), quanto por Moon e Kym (2006).

O que se buscará a seguir é realizar uma análise comparativa entre os indicadores do modelo proposto (Default Model) com outros modelos teóricos gerados pelo próprio software.

Na tabela 03, a seguir, são apresentadas três possibilidades de modelo (em algumas situações apenas duas), servindo de comparação entre eles. O Modelo Proposto ou o modelo pretendido é denominado de Default Model; o Modelo Ideal é denominado de Saturated Model; e o Modelo Pobre, denominado Independence Model. O objetivo do Modelo Proposto é aproximar-se o máximo possível do Modelo Ideal, consubstanciando-se em robustez, confiabilidade e, principalmente, generalização. No modelo saturado, qualquer conjunto de dados se ajusta tranqüilamente, isso é, ele é o mais generalizado possível (quanto mais generalizável, melhor será o modelo). Já o Modelo Pobre ou Independente é exatamente o contrário, com nenhuma correlação entre as variáveis e altamente específico.

Tabela 03: Estatística do modelo estrutural.

Modelos
Indicadores




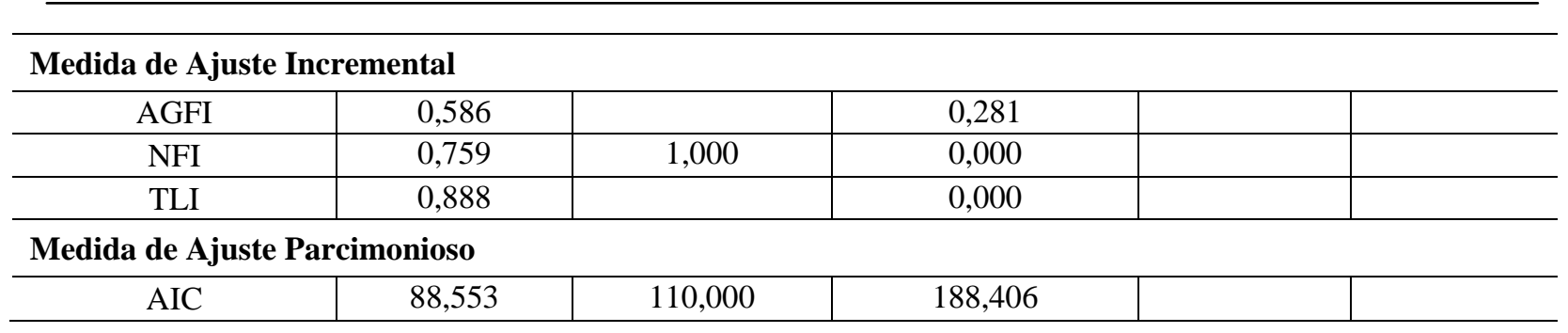

\section{$\checkmark$ Medida de ajuste absoluto}

Tais medidas buscam determinar em que grau o modelo proposto prevê a matriz de correlação observada. Normalmente, essas medidas são altamente influenciadas pelo tamanho da amostra.

\section{$\checkmark$ Medida de ajuste incremental}

O objetivo dessas medidas é avaliar a qualidade do modelo gerado comparativamente a outros modelos alternativos. Nesse caso, o modelo gerado é diretamente comparado com os modelos Saturated Model e Independence Model.

\section{$\checkmark$ Medida de ajuste parcimonioso}

Também voltado genericamente para a comparação entre modelos, seu objetivo maior é diagnosticar se o ajuste ou a qualidade do modelo foi conseguido através do superajustamento dos dados, ou seja, através da inclusão de mais coeficientes. Sua filosofia é semelhante ao $\mathrm{R}^{2}$.

\subsection{Avaliação do modelo estrutural}

Apesar de não ser recomendado o uso de SEM em amostras pequenas (menor que 100), uma vez que pode provocar problemas de especificação, esse problema pode ser atenuado quando a SEM atua exclusivamente como um modelo confirmatório. Ficou demonstrado que, quando seguida de uma rígida análise exploratória, definindo os construtos através da análise fatorial e considerando, também, a boa qualidade da amostra, isso é, uma amostra bastante homogênea, o modelo estrutural gerado tenderá a ser, também, de boa qualidade. Com isso, o modelo aqui apresentado, mesmo com amostra relativamente pequena, foi considerado aceitável, quando confrontado com modelos alternativos, porém poderia ser melhorado quando da ampliação da amostra, talvez não limitado a um cluster, mas para uma população mais abrangente envolvendo outras regiões.

Vale salientar, também, que, por se tratar de uma pesquisa exploratória, todos os resultados alcançados podem e devem ser avaliados com bastante cuidado, porém os resultados aqui apresentados garantem uma considerável qualidade do modelo, podendo ser, quando ajustado a alguma especificidade pontual, aplicados, também, a outros segmentos da economia que se configurem como intensivos em capital intangível.

\section{CONCLUSÕES}

Através dessa pesquisa, constatou-se que, especificamente para empresas de TIC, que o valor do intangível é formado por quatro direcionadores, sendo eles: Capital Humano, 
Gestão do Capital Humano, Capital Estrutural e Ambiente Organizacional. Essa ordem de apresentação também representa a ordem de importância na formação do valor total criado. Com isso, a pesquisa procurou aprofundar o tema, pois os construtos mais divulgados e considerados pelos pesquisadores incorporam apenas três dimensões: Capital Intelectual, Capital Relacional e Capital Estrutural (como os apresentados nos modelos de Moon e Kym, 2006; e Bontis, 1998), desta forma, esta pesquisa avança em apresentar quatro fatores, não porque quanto maior o número de construto melhor será o modelo, mas porque consegue evidenciar outros construtos relevantes para a indústria pesquisada, enriquecendo ainda mais o conjunto de determinantes do valor do intangível. Isto faz com que haja maior transparência na identificação do intangível.

Entende-se, todavia, que a complexidade que envolve o capital intangível é muito elevada, por isso, optou-se por desmembrar o máximo possível, as dimensões, respeitando seus fundamentos, suas lógicas e a segurança estatística quando possível.

Desta forma, conclui-se que este estudo contribuirá para o processo de valuation em empresas intensivas em capital intangível, especificamente empresa de TIC, indicando quais os fatores determinantes da criação de valor e quais os tópicos ou fatores considerados mais relevantes, apresentando aos gestores dessas mesmas empresas quais as variáveis que formam tais determinantes. Isso fará com que esses mesmos gestores possam envidar esforços para maximizar tais variáveis (no sentido de explorar ao máximo seu significado) e fortalecer aquelas nas quais a empresa não consegue gerenciar de forma adequada.

Finalizando essa pesquisa, espera-se ter contribuído para o incremento da teoria sobre Avaliação de Empresas e também sobre Gestão do Conhecimento, apresentando um instrumento que poderá ser utilizado tanto pela academia como pelos profissionais que atuam não apenas na área de investimentos, mas também, por aqueles que se interessam pela gestão do conhecimento e do capital intelectual. A título de sugestões para trabalhos posteriores, seria bastante relevante, quantificar as variáveis utilizadas nessa pesquisa, gerando modelos quantitativos que possam de forma direta, determinar o valor do ativo intangível de empresas de tecnologia da informação e comunicação.

\section{REFERÊNCIAS}

ARANHA, Francisco; ZAMBALDI, Felipe. Análise fatorial em administração. São Paulo: Cengage Learning, 2008.

ARBUCKLE, James L. AMOS user's guide: version 6.0. Chicago, IL: SPSS, 2005.

BONTIS, Nick. Intellectual capital: an exploratory study that develops measures and model. Management Decision. v. 36, n. 2, p. 63-76, 1998.

BONTIS, Nick. Assessing knowledge assets: a review of the models used to measure intellectual capital. International Journal of Management Reviews. v. 3, n. 1, p. 41-60, 2001.

BRYNJOLFSSON, Erik; HITT, Lorin M.; YANG, Shinkyu. Intangible assets: computers and organizational capital. Brookings Papers on Economic Activity; n.01, p.137-198, 2002.

CARDOSO, Leonor M. G. P. P. A. Gerir conhecimento e gerar competitividade: estudo empírico sobre a gestão do conhecimento e seu impacto no desempenho organizacional. Tese de doutorado (Psicologia). Universidade de Coimbra, 2003. 
CHANG, Jow-Ran; HUNG, Mao-Wei; TSAI, Feng-Tse. Valuation of intellectual property: a real option approach. Journal of Intellectual Capital. n. 6. v. 3. p. 339-356, 2005.

CORNELL, Bradford. Corporate valuation: tool for effective appraisal and decision making. Chicago: Irwin Professional Publishing, 1993.

EDVINSSON, Leif; MALONE, Michael S. Capital intelectual: descobrindo o valor real de sua empresa pela identificação de seus valores internos. São Paulo: Makron Books, 1998.

FELTHAM, Gerald A.; OHLSON, James A. Valuation and clean surplus accounting for operating and financial activities. Contemporary Accounting Research. v. 11, n. 2, p. 689731, Spring, 1995.

HAIR, J.F.; ANDERSON, R.E.; TATHAN, R.L.; BLACK, W.C. Análise multivariada de dados. 5. ed. Porto Alegre: Bookman, 2005;

HSU, Chung-Cheng. The influence of dimensions of corporate governance on firm value using an applied structural equation model. Journal of American Academy of Business. v. 11, n. 1, marc, 2007.

KAPLAN, Robert S.; NORTON, David P. The balance scorecard: measures that drive performance. Harvard Business Review. v. 70, n. 1, p. 71-79, 1992.

KAYO, Eduardo Kazuo. A estrutura de capital e o risco das empresas tangível e intangível-intensivas: uma contribuição ao estudo da valoração de empresas. Tese (Doutorado em Administração) - Faculdade de Economia, Administração e Contabilidade, Universidade de São Paulo, 2002.

KAYO, Eduardo Kazuo; KIMURA, Herbert; MARTIN, Diógenes M. L.; NAKAMURA, Wilson T. Ativos intangíveis, ciclo de vida e criação de valor. Revista de Administração Contemporânea (RAC), v. 10, n. 003, p. 73-90, 2006.

KLINE, R. B. Principles and practice of structural equation modeling. Second edition. New York, The Guilford Press, 2005.

KUHN, Thomas S. A estrutura das revoluções científicas. 9. ed. São Paulo: Editora Perspectiva, 2005.

LEV, Baruch (a). Measuring the value of intellectual capital. Ivey Business Journal. v. 65, n. 4, p. 16-20. Mar/Apr. 2001.

(b). Intangibles: management, measurement, and reporting. Brookings Institution Press, Washington, 2001.

MOON, Yun Ji; KYM, Huo Gun. A model for the value of intellectual capital. Canadian Journal of Administrative Sciences. v. 23. n. 3, p. 253-269, 2006.

PEREZ, Marcelo Monteiro; FAMÁ, Rubens. Ativos intangíveis e o desempenho empresarial. Revista de Contabilidade e Finanças - USP, São Paulo, v. 17, n. 40, p. 7-24, Jan./Abr. 2006.

REILLY, Robert F.; SCHWEIHS, Robert P. Valuing intangible assets. New York: McGrawHill, 1998.

SHIU, Huci-Jen. The application of the value added intellectual coefficient to measure corporate performance: evidence from technological firms. International Journal of Management. v. 23. n. 2, p. 356-365, 2006. 
O CAPITAL INTELECTUAL E A FORMAÇÃO DE VALOR EM EMPRESAS INTENSIVAS EM CAPITAL DE RISCO

STEWART, Thomas A. Capital intelectual: a nova vantagem competitiva das empresas. Rio de Janeiro: Campus, 1998.

SVEIBY, Karl. E. The new organizational wealth: managing and measuring. San Francisco: Barrett-Koehler, 1997.

VIGORONA, Fernando. Capital intelectual. Raíces ocultas del valor de las empresas. Pharos. Santiago - Chile, vol. 11, n. 001, mayo-junio, p. 51-65, 2004. 